\title{
EVALUATING THE SAFETY PERFORMANCE OF CHINA'S PROVINCIAL CONSTRUCTION INDUSTRIES FROM 2009 TO 2017
}

\author{
Liangguo $\mathrm{KANG}^{1,2^{*}}$, Chao WU $\mathrm{W}^{1,2}$ \\ ${ }^{1}$ School of Resources and Safety Engineering, Central South University, Changsha, P. R. China \\ ${ }^{2}$ Safety \& Security Theory Innovation and Promotion Center, Central South University, Changsha, P. R. China
}

Received 3 July 2019; accepted 18 December 2019

\begin{abstract}
Performance evaluation in construction safety is of great importance to further improve upon safety management processes. This paper develops a data envelopment analysis (DEA) based framework to evaluate the construction safety performance at the macro level. The core of the method is to compare the output-input ratio of construction safety. Using the building practitioner, construction machinery and equipment, and construction area as the inputs, and value added of construction and death toll as the outputs, safety performance score is computed for the China's provincial construction industries from 2009 to 2017. The results show that the number of benchmark provinces every year is between five and seven. The gap between the best-performing and underperforming province was relatively small in 2012 and big in 2014. Beijing, Qinghai, Hainan, Fujian, Chongqing, and Tianjin can be utilized as role models for the provinces that need to improve their performance in construction safety. The eastern region has the highest score in construction safety performance, followed by the western and central region. This study provides an effective solution to solve performance issue in regional construction safety and improves the tradition performance evaluation system to a certain extent.
\end{abstract}

Keywords: safety performance, performance evaluation, output-input ratio, data envelopment analysis, construction safety.

\section{Introduction}

The construction industry is one of the 20 industrial categories in China's economy (General Administration of Quality Supervision, Inspection and Quarantine of PRC [GAQSIQ], 2017), which plays an important role in the economic development. Meanwhile, construction is a high-risk industry. The number of deaths in the construction industry ranking first out of all the industrial production sectors in China since 2012 (Zhang et al., 2019a). And the construction industry has the highest fatality rates in many regions, including Australia, Europe, and North America (McCabe et al., 2016; Choudhry, 2017). Safety is critical to the construction industry (Nahangi et al., 2019). The emphasis on construction safety has increased mainly in the aspect of safety performance (Awolusi \& Marks, 2016). Also, the evaluation of safety performance is an important guidance to construction safety management (Zhang et al., 2019b; Ji et al., 2019). Most construction safety performance commonly used are OSHA recordable incidence rates and experience modification rating (Wanberg et al., 2013). These partial-factor indicators have their own advantages and disadvantages as academic scholars investigate further (Stern, 2012). Many academic schol- ars found that partial-factor indicators were not applicable and might be misleading ( $\mathrm{Hu} \&$ Wang, 2006; Boyd, 2008), for example, it is obviously improper to compare the safety performance of decision-making units (DMUs) by means of only the fatality numbers or rates because they ignore the amount of exposure to risk in construction safety. The total-factor indicators which are based on multiple input-output systems, can effectively remedy the shortage of partial-factor indicators, and have been applied for performance evaluation by many scholars (Feng \& Wang, 2017).

Data envelopment analysis (DEA) has been recognized as an effective method to analyze the safety performance by using total-factor indicators (El-Mashaleh et al., 2007). Since there is no need to make assumptions about the input and output, the DEA model excludes many subjective factors and has good objectivity in practical applications (Geng et al., 2019). DEA method extensively applied to solve the performance issue that exist in various industries, for example, the construction industry (Feng \& Wang, 2017), the petrochemical industry (Han et al., 2019), and the coal mining industry (Li et al., 2019). Fur-

*Corresponding author. E-mail: kangliangguo@csu.edu.cn 
thermore, many academic scholars utilize DEA method to solve performance problems in safety management (Nazarko \& Chodakowska, 2017; Tatari et al., 2016), for example, the construction safety performance (Nahangi et al., 2019), the road safety performance (Ganji \& Rassafi, 2019), and the airlines safety performance (Barak \& Dahooei, 2018). There are many studies evaluating the road safety performance at the macro level. For example, Shen et al. (2012) applied DEA model to evaluate road safety performance of $27 \mathrm{EU}$ countries, which gives a practical yet challenging target for each underperforming country. Bastos et al. (2015) applied DEA model to evaluate road safety performance of 27 Brazilian states, which indicates that creating a trustworthy ranking is valuable for nationwide road safety planning. Ganji and Rassafi (2019) applied DEA model to evaluate road safety performance of 31 Iranian provinces, and analyze the productivity of safety programmes in reducing the number of road fatalities.

However, as opposed to the road safety performance evaluation, most of the studies currently on construction safety performance are at enterprise micro-level. For instance, El-Mashaleh et al. (2010) utilized DEA method to evaluate safety performance of 45 construction contractors, which provides quantitative guidance on how to minimize the number of suffered accidents. Dou and Zheng (2011) used DEA method to evaluate safety performance of four contractors, which shows that this method is objective and reasonable for contractor safety performance evaluation. Nahangi et al. (2019) developed a DEA-based framework to evaluate the safety-based efficiency of construction sites, and the number of incidents is the dominant factor correlating with the efficiency of construction sites. In addition, many scholars utilized DEA method to measure the productivity, the energy efficiency, and the carbon emission efficiency of the regional construction industry (Xue et al., 2008; Chen et al., 2016; Feng \& Wang, 2017; Zhou et al., 2019), which provides reference and inspiration for conducting the research on construction safety performance. Therefore, it is necessary for developing a DEA-based framework to evaluate the construction safety performance at the macro level, which expands the boundary of construction safety knowledge into a macro level. Also, it requires to identify the input and output indicators for regional construction safety performance due to a lack of the similar research. Take China as an example, this study develops a DEA-based construction safety framework, which evaluates provincial construction safety performance from 2009 to 2017.

The contributions of this paper are as follows: (i) its presentation of a DEA-based framework to evaluate the construction safety performance at the macro level, by considering both the desirable output and the outputinput ratio, which can improve the tradition performance evaluation system to a certain extent. Also, this framework have reference values for evaluating the safety performance in other countries or regions. (ii) Its analysis of safety performance of the China's provincial construction industries over the past nine years, which helps the international readers understand the safety situation in China's provincial construction industries. (iii) Its discovery of the benchmark provinces, which enables the underperforming provinces to recognize the gap with those benchmark ones and further develop their own construction safety strategy.

\section{Methods and data sources}

\subsection{Research framework}

Because the core of this study is to compare the outputinput ratio of the DMUs, it is first necessary to identify the inputs and outputs of China's provincial construction safety performance. Traditional partial-factor indicators of China's construction safety performance include death toll, injury rate of per one thousand persons, mortality rate of per ten thousand persons, mortality rate of per ten billion output values, and mortality rate of per one hundred thousand square meters (Wang et al., 2012). Furthermore, in the work safety process, people and objects interact, which is also expressed in the customary designation "people-machine-environment" system (Liu et al., 2016; Kang et al., 2019). The amount of exposure to risk are discussed from these three aspects, for example, the population size, the number of registered vehicles, and the distance travelled are the three most frequently used road risk indicators (Shen et al., 2012). Similarity, building practitioner (BP), construction machinery and equipment (CME), and construction area (CA) are the three used the amount of exposure to risk in construction safety. For one thing, the raw data of three indicators were obtained from the "China Statistical Yearbook", which ensures the reliability and availability of data. For another, BP, CME, and $\mathrm{CA}$ represent the key factors of safety management such as people, machine, and environment respectively. Therefore, this paper selects three indicators as inputs, i.e., BP, $\mathrm{CME}$, and CA.

Outputs include both the desirable and undesirable output in many studies, and desirable output is usually economic benefit of the DMUs (Feng \& Wang, 2017; Han et al., 2018). Similarity, outputs of safety performance are discussed from desirable and undesirable output of the construction industry. This paper selects two indicators as outputs, i.e., death toll (DT), and value added of construction (VAC). DT, and VAC express the undesirable, and desirable output respectively of the construction industry.

Inputs are discussed from $\mathrm{BP}, \mathrm{CME}, \mathrm{CA}$, and outputs are discussed from VAC, DT, as shown in Figure 1. So, the research framework may be mathematically presented as:

$\mathrm{F}(\mathrm{VAC}, \mathrm{DT})=\mathrm{f}(\mathrm{BP}, \mathrm{CME}, \mathrm{CA})$.

The input and output of the research framework are explained as follows:

- BP in this study refers to the number of employees in the construction industry. It assumes the all workers are exposed to the risk of being killed in a construction accident. In addition, population has been used in the input indicator for road safety performance (Bastos et al., 2015; Shen et al., 2012). 
- CME in this study refers to the number of machinery and equipment in the construction industry. Similar to the number of motor vehicles were used as the inputs in terms of road safety performance (Bastos et al., 2015; Shen et al., 2012), it assumes the risk of a construction fatality is related to the number of machinery and equipment owned by the construction industry.

- CA in this study refers to the workload in construction activity. CA indirectly shows the complex environment in the construction activity, such as the climatic environment (e.g., weather, temperature) and the working environment (e.g., edge-near, opening, climbing, hanging, and cross operation) (Ministry of Housing and Urban-Rural Development of PRC [MOHURD], 2016). It assumes the risk of a construction fatality is related to the area of the building construction.

- DT. Because there are difficulties in collecting the number of injuries or occupational diseases in the construction industry, only DT is taken as undesirable output in the performance evaluation. Also, DT is an essential indicator of the performance in construction safety (Wang et al., 2018). The number of fatalities has been used in the output indicator for road safety performance (Bastos et al., 2015; Shen et al., 2012) and construction safety performance (El-Mashaleh et al., 2010).

- VAC. In China, the final result of the activities of production and management of construction in monetary terms in the reference period is expressed as VAC (National Bureau of Statistics of PRC, 2018). Economic development is a priority of all levels of government, and irrespective of country, constitution or system of governance (Pugalis \& Tan, 2017). The goals for economic growth and accident prevention should be put together in order to sustain the longterm development of the construction industry $(\mathrm{Hu}$ \& Wang, 2006). Due to the uneven development of regions, VAC can reflect the frequent degree of construction activities. More construction activities will be increasing the number of fatalities in the case of the same of casualty rate of DMUs.

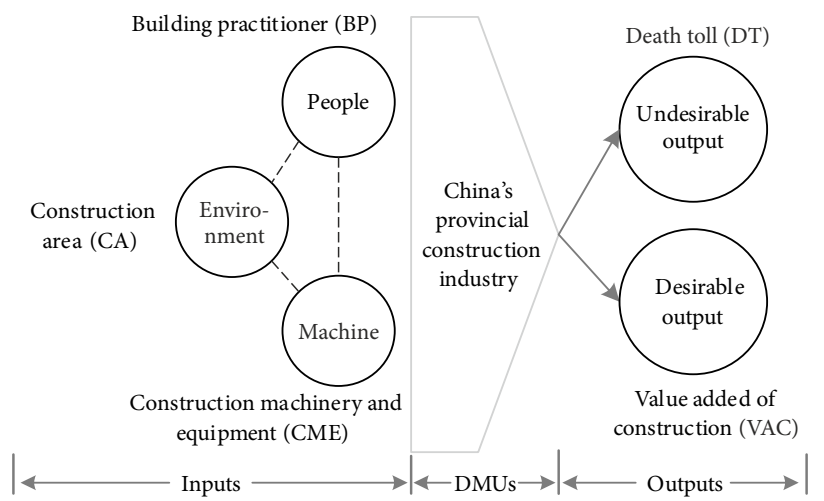

Figure 1. The input and output of the research framework

\subsection{Research methods}

DEA became the principal method for measuring efficiency related to multiple inputs and outputs in the construction industry (Hu \& Liu, 2018). DEA is a nonparametric linear programming approach, and the set of DMUs under study form an envelopment surface. A DMU that lie on the surface is termed efficient and do not lie on the surface is termed inefficient. DEA is used to evaluate the relative effectiveness of DMUs (Geng et al., 2017), and the score of a DMU varies between 0 and 1 . The score of a DMU equal to 1 is capable to convert all its inputs into outputs compared to the rest of DMUs, and the DMU lie on the envelopment surface.

There are three possible types of returns to scale in terms of performance evaluation: increasing returns to scale, constant returns to scale, and decreasing returns to scale (Kang et al., 2020). The safety performance is evaluated by assuming a constant return to scale (CRS) DEA model when taking into consideration of competition fairness among all DMUs. Also, the CRS model is widely used to construction or road safety performance evaluation in the previous studies (El-Mashaleh et al., 2010; Shen et al., 2012; Ganji \& Rassafi, 2019; Nahangi et al., 2019). It is why rule out the other options such as variable return to scale (VRS) model and slack based measure (SBM) model. In order to promote economic development, especially the economic development of less developed provinces, it requires that more capital, material, and human resources are put into the construction industry. Hence, it was evaluated by an output-oriented DEA model, namely the maximum increase of output in the same input. However, DT is undesirable output in this study, less is better, which cannot apply to the output principle (i.e., more is better) in the DEA model. Hence, the raw data of undesirable output need to be preprocessed when using the DEA method. In order to compare the percentage change of DMUs in terms of the same indicators, the input and desirable output data is also preprocessed.

We consider that we have $n$ DMUs to be evaluated in terms of $m$ inputs and $s$ outputs, where $X_{i}$ are denoted by inputs and $Y_{r}$ are denoted by outputs. In addition, $Y_{p}$ are denoted by desirable outputs, $Y_{b}$ are denoted by undesirable outputs, and the conditions must be satisfied: $Y_{p} \in Y_{r}$, $Y_{b} \in Y_{r} . X_{i}, Y_{r}$ may be presented as:

$$
\begin{aligned}
X_{i} & =\left(X_{i 1}, X_{i 2}, \ldots, X_{i n}\right)(i=1,2, \ldots, m) ; \\
Y_{r} & =\left(Y_{r 1}, Y_{r 2}, \ldots, Y_{r n}\right)(r=1,2, \ldots, s) .
\end{aligned}
$$

Preprocessing of input data is mathematically presented as:

$$
x_{i}=\left(\frac{100 \times X_{i 1}}{\sum_{j=1}^{n} X_{i j}}, \frac{100 \times X_{i 2}}{\sum_{j=1}^{n} X_{i j}}, \ldots, \frac{100 \times X_{i n}}{\sum_{j=1}^{n} X_{i j}}\right) .
$$


Preprocessing of desirable output data is mathematically presented as:

$$
y_{p}=\left(\frac{100 \times Y_{p 1}}{\sum_{j=1}^{n} Y_{p j}}, \frac{100 \times Y_{p 2}}{\sum_{j=1}^{n} Y_{p j}}, \ldots, \frac{100 \times Y_{p n}}{\sum_{j=1}^{n} Y_{p j}}\right) .
$$

Due to undesirable output data cannot be used in the DEA model, the way to address this is to turn undesirable output into desirable output by means of data reciprocal transformation (Seiford \& Zhu, 2002). After the necessary data reciprocal transformation, undesirable output data could achieve the goal that more is better, and can be used in the DEA model. Data reciprocal transformation of undesirable output can be mathematically presented as:

$\mathrm{D}_{b}=\frac{\sum_{j=1}^{n} Y_{b j}}{Y_{b 1}}+\frac{\sum_{j=1}^{n} Y_{b j}}{Y_{b 2}}+\ldots+\frac{\sum_{j=1}^{n} Y_{b j}}{Y_{b n}} ;$

$y_{b}=\left(\frac{\sum_{j=1}^{n} Y_{b j}}{100 \times \frac{\sum_{j=1}^{n} Y_{b j}}{Y_{b 1}}}, \frac{100 \times \frac{Y_{b 2}}{\mathrm{D}_{b}}, \ldots, \frac{\sum_{j=1}^{n} Y_{b j}}{\mathrm{Y}_{b n}}}{\mathrm{D}_{b}}\right)$.

Raw data were preprocessed to achieve dimensionless data, which can be presented as follows:

$$
\begin{aligned}
& x_{i}=\left(x_{i 1}, x_{i 2}, \ldots, x_{i n}\right)(i=1,2, \ldots, m) ; \\
& y_{r}=\left(y_{r 1}, y_{r 2}, \ldots, y_{r n}\right)(r=1,2, \ldots, s) .
\end{aligned}
$$

DEA-based construction safety model will automatically choose the best possible input and output weights under the imposed restrictions to maximize the performance score of a certain DMUs (El-Mashaleh et al., 2010). The researcher is no need to assign weights to the different inputs and outputs. $\mathrm{DMU}_{2}$ could take $\mathrm{DMU}_{1}$ as a benchmark for improving its construction safety performance if $\mathrm{DMU}_{1}$ is efficient and $\mathrm{DMU}_{2}$ is inefficient. Construction safety performance was evaluated by an output-oriented CRS DEA model. Mathematically, safety performance score (SPS) can be characterized as:

$$
\begin{aligned}
& \text { SPS }=\max \theta ; \\
& \text { s.t. }\left\{\begin{array}{l}
\sum_{j=1}^{n} \lambda_{j} x_{i j} \leq x_{i 0}, i=1,2, \ldots, m \\
\sum_{j=1}^{n} \lambda_{j} y_{r j} \geq \theta y_{r 0}, r=1,2, \ldots, s \\
\lambda_{j} \geq 0, j=1,2, \ldots, n
\end{array},\right.
\end{aligned}
$$

where $\theta$ refers to the measure of efficiency for $\mathrm{DMU}_{0}$ (the DMU under evaluation) which is a member of the set $j=1,2, \ldots, n ; \lambda_{j}$ refers to the weight produced by $\mathrm{DMU}_{j} ; x_{i 0}, y_{r 0}$ refer to the known $i$ th input and $r$ th output, respectively, produced by $\mathrm{DMU}_{0} ; x_{i j}, y_{r j}$ refer to the known $i$ th input and $r$ th output respectively produced by $\mathrm{DMU}_{j}$.

The model yields SPS that range between 0 and 1.0, with more scores improves safety performance. The DMU is considered efficient when its SPS is 1.0. The step of construction safety performance evaluation based on DEA model is described as Figure 2.

\subsection{Data sources}

Due to the lack of complete data, the industries of Tibet, Hong Kong, Macao, and Taiwan were excluded from our samples. Thus, the samples in this study consist of 30 provinces in China from 2009 to 2017, resulting in 270 observations. There were three inputs, BP, CME, and CA, a desirable output of VAC, and an undesirable output of DT. The sources of data on inputs and outputs are as follows:

(i) Data on BP, CME, CA, and VAC were obtained from the "China Statistical Yearbook 2010-2018" issued by the National Bureau of Statistics of PRC (2018).

(ii) Data on DT were obtained from the "Annual Notification of Construction Accidents between 2009 and 2017" issued by the Ministry of Housing and Urban-Rural development of PRC.

Table 1 shows the data statistics of inputs and outputs in China's provincial construction safety performance between 2009 and 2017. To identify the difference of construction safety performance among regions, our sample should be grouped. According to the previous studies, 30 provinces were divided into three main regions: the eastern, central, and western region (Feng et al., 2017), which can be expressed in Table 2 .

\section{Results and analysis}

\subsection{Safety performance score}

Table 3 summarizes the descriptive statistics of the evaluation results in China's provincial construction safety performance from 2009 to 2017 . Out of 30 provinces, only $7,6,6,7,6,5,5,6$, and 6 provinces are efficient respectively in safety performance during 2009 and 2017. These efficient provinces have a SPS $=1.0$. The maximum score of safety performance is 1.0 , and the minimum score is 0.411 . The gap between the best-performing and underperforming province was relatively small in 2012 and big in 2014.

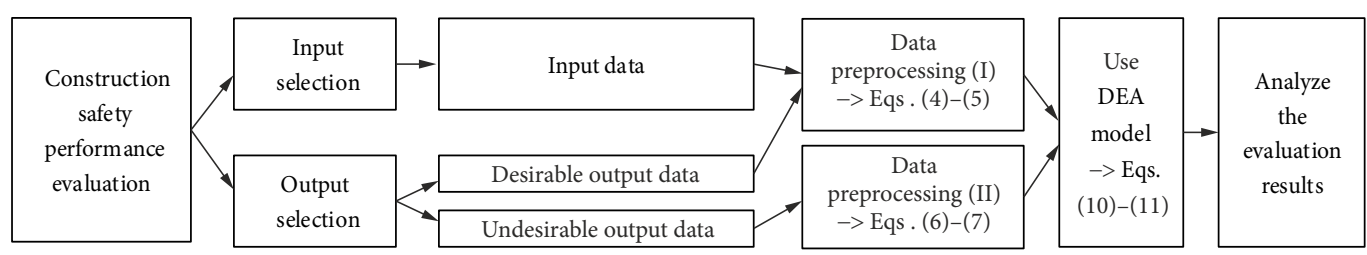

Figure 2 . The step of construction safety performance evaluation 
Table 1. Data statistics of inputs and outputs

\begin{tabular}{|l|c|c|c|c|c|}
\hline \multirow{2}{*}{ Variable } & \multicolumn{3}{|c|}{ Inputs } & \multicolumn{2}{c|}{ Outputs } \\
\cline { 2 - 6 } & BP $\left(10^{4}\right.$ persons $)$ & CME $\left(10^{4}\right.$ units $)$ & CA $\left(10^{6} \mathrm{~m}^{2}\right)$ & VAC $\left(10^{8}\right.$ CNY $)$ & DT (persons) \\
\hline Max & 792.89 & 193.66 & 2320.34 & 6717.06 & 118 \\
\hline Min & 5.48 & 0.71 & 4.91 & 21.45 & 3 \\
\hline Median & 95.69 & 19.34 & 225.81 & 641.13 & 20 \\
\hline Mean & 150.98 & 34.84 & 345.73 & 980.87 & 23.47 \\
\hline StDev & 166.47 & 35.56 & 429.32 & 1110.81 & 15.10 \\
\hline
\end{tabular}

Table 2. Three main regions and their provinces

\begin{tabular}{|l|l|}
\hline \multicolumn{1}{|c|}{ Region } & \multicolumn{1}{c|}{ Province } \\
\hline Eastern region (11 provinces) & $\begin{array}{l}\text { Beijing, Tianjin, Hebei, Liaoning, Shanghai, Jiangsu, Zhejiang, Fujian, Shandong, Guangdong, } \\
\text { Hainan }\end{array}$ \\
\hline Central region (8 provinces) & Jilin, Heilongjiang, Anhui, Jiangxi, Henan, Hubei, Hunan, Shanxi \\
\hline Western region (11 provinces) & $\begin{array}{l}\text { Inner Mongolia, Chongqing, Sichuan, Guizhou, Yunnan, Shaanxi, Gansu, Qinghai, Ningxia, } \\
\text { Xinjiang, Guangxi }\end{array}$ \\
\hline
\end{tabular}

Table 3. Descriptive statistics for evaluation results

\begin{tabular}{|l|c|c|c|c|c|c|c|c|c|}
\hline \multicolumn{1}{|c|}{ Descriptive } & 2009 & 2010 & 2011 & 2012 & 2013 & 2014 & 2015 & 2016 & 2017 \\
\hline Total number of DMUs & 30 & 30 & 30 & 30 & 30 & 30 & 30 & 30 & 30 \\
\hline Number of efficient DMUs & 7 & 6 & 6 & 7 & 6 & 5 & 5 & 6 & 6 \\
\hline Number of inefficient DMUs & 23 & 24 & 24 & 23 & 24 & 25 & 25 & 24 & 24 \\
\hline Scores average & 0.743 & 0.707 & 0.733 & 0.773 & 0.738 & 0.692 & 0.711 & 0.742 & 0.715 \\
\hline Scores standard deviation & 0.202 & 0.224 & 0.188 & 0.168 & 0.168 & 0.177 & 0.171 & 0.170 & 0.175 \\
\hline Maximum score & 1.0 & 1.0 & 1.0 & 1.0 & 1.0 & 1.0 & 1.0 & 1.0 & 1.0 \\
\hline Minimum score & 0.49 & 0.426 & 0.456 & 0.506 & 0.438 & 0.411 & 0.447 & 0.475 & 0.46 \\
\hline
\end{tabular}

The number of benchmark provinces every year is between five and seven. So, there is much room to improve construction safety performance among most provinces. In addition, the average of the scores is 0.728 , which means that the output for an average province could be increased by $27.2 \%$.

Table 4 shows SPS of China's provincial construction industries from 2009 to 2017 . The results show how each province performs in construction safety compared to the rest of the provinces. It can be found that the performance score of construction safety for most provinces vary from year to year. Only the performance score of two provinces are the same (i.e., all efficient) in terms of construction safety over the past nine years. Specifically, Beijing and Qinghai were considered to have better safety performance in that nine-year period, and they are more efficient in converting the input invest of construction activity into more economic benefits or less accidents. In addition, it can be found that some benchmark DMUs in one year may not be the ones in the next year. This findings is similar to road safety evaluation in the previous studies (Shen et al., 2013). Specifically, Hainan, Ningxia, Tianjin, Fujian, Chongqing, Jilin, Xinjiang, Heilongjiang, Shanghai, and Inner Mongolia were benchmark provinces over the past eight, six, four, four, four, three, three, two, one, and one years respectively.
In Figure 3 we depicted the average of SPS in China's provincial construction industry between 2009 and 2017. It can be inferred that Beijing, Qinghai, Hainan, Chongqing, and Fujian ranked the top five, so that they can be utilized as role models for the other 25 provinces. In addition, Guizhou, Gansu, Hunan, Guangxi, and Hebei were at the bottom five, so that they need urgently to improve the condition of construction safety. Because average score may ignore some crucial piece of information, it is very necessary to use data analytic method to group the performance of China's provincial construction industries.

\subsection{Provinces clustering}

Clustering analysis is conducted to group the provinces with inherent similarity in their performance. The intention is to sort the provinces into groups in such a way that the degree of "natural association" is high among members of the same group and low among members from different groups (Bastos et al., 2015). The advantage of clustering is to offer a more feasible basis for the transference of good experiences from best-performing to underperforming provinces. The results of cluster analysis on safety performance of China's provincial construction industries between 2009 and 2017 show in Figure 4. 
Table 4. SPS of China's provincial construction industries from 2009 to 2017

\begin{tabular}{|c|c|c|c|c|c|c|c|c|c|c|c|}
\hline Region & Province & 2009 & 2010 & 2011 & 2012 & 2013 & 2014 & 2015 & 2016 & 2017 & Mean \\
\hline \multirow{11}{*}{$\begin{array}{l}\text { Eastern } \\
\text { region }\end{array}$} & Beijing & 1 & 1 & 1 & 1 & 1 & 1 & 1 & 1 & 1 & 1 \\
\hline & Tianjin & 0.938 & 0.707 & 1 & 1 & 1 & 1 & 0.858 & 0.795 & 0.721 & 0.891 \\
\hline & Hebei & 0.554 & 0.449 & 0.517 & 0.506 & 0.438 & 0.411 & 0.458 & 0.475 & 0.46 & 0.474 \\
\hline & Liaoning & 0.892 & 0.741 & 0.717 & 0.831 & 0.763 & 0.575 & 0.704 & 0.672 & 0.605 & 0.722 \\
\hline & Shanghai & 1 & 0.91 & 0.867 & 0.892 & 0.757 & 0.713 & 0.837 & 0.907 & 0.785 & 0.852 \\
\hline & Jiangsu & 0.667 & 0.527 & 0.559 & 0.664 & 0.572 & 0.563 & 0.627 & 0.699 & 0.679 & 0.617 \\
\hline & Zhejiang & 0.625 & 0.643 & 0.649 & 0.744 & 0.686 & 0.634 & 0.567 & 0.608 & 0.57 & 0.636 \\
\hline & Fujian & 0.773 & 0.824 & 0.794 & 1 & 1 & 1 & 0.917 & 0.919 & 1 & 0.914 \\
\hline & Shandong & 0.591 & 0.461 & 0.545 & 0.588 & 0.611 & 0.578 & 0.604 & 0.632 & 0.597 & 0.579 \\
\hline & Guangdong & 0.659 & 0.555 & 0.652 & 0.775 & 0.678 & 0.682 & 0.792 & 0.782 & 0.741 & 0.702 \\
\hline & Hainan & 1 & 1 & 1 & 1 & 1 & 1 & 1 & 1 & 0.888 & 0.988 \\
\hline \multirow{8}{*}{$\begin{array}{l}\text { Central } \\
\text { region }\end{array}$} & Jilin & 0.984 & 1 & 1 & 1 & 0.842 & 0.739 & 0.724 & 0.732 & 0.706 & 0.859 \\
\hline & Heilongjiang & 1 & 1 & 0.755 & 0.852 & 0.698 & 0.699 & 0.636 & 0.716 & 0.699 & 0.784 \\
\hline & Anhui & 0.6 & 0.478 & 0.577 & 0.578 & 0.593 & 0.578 & 0.619 & 0.646 & 0.597 & 0.585 \\
\hline & Jiangxi & 0.548 & 0.444 & 0.515 & 0.738 & 0.648 & 0.666 & 0.617 & 0.617 & 0.583 & 0.597 \\
\hline & Henan & 0.601 & 0.516 & 0.566 & 0.577 & 0.586 & 0.556 & 0.582 & 0.795 & 0.725 & 0.612 \\
\hline & Hubei & 0.621 & 0.543 & 0.711 & 0.725 & 0.684 & 0.538 & 0.646 & 0.613 & 0.581 & 0.629 \\
\hline & Hunan & 0.501 & 0.426 & 0.525 & 0.548 & 0.586 & 0.535 & 0.537 & 0.523 & 0.474 & 0.517 \\
\hline & Shanxi & 0.637 & 0.694 & 0.722 & 0.7 & 0.603 & 0.638 & 0.605 & 0.623 & 0.564 & 0.643 \\
\hline \multirow{11}{*}{$\begin{array}{l}\text { Western } \\
\text { region }\end{array}$} & Inner Mongolia & 1 & 0.962 & 0.958 & 0.839 & 0.902 & 0.753 & 0.736 & 0.823 & 0.783 & 0.862 \\
\hline & Chongqing & 0.801 & 0.96 & 0.839 & 0.863 & 1 & 0.995 & 1 & 1 & 1 & 0.940 \\
\hline & Sichuan & 0.503 & 0.743 & 0.706 & 0.807 & 0.727 & 0.551 & 0.577 & 0.56 & 0.485 & 0.629 \\
\hline & Guizhou & 0.504 & 0.447 & 0.555 & 0.646 & 0.651 & 0.534 & 0.447 & 0.516 & 0.647 & 0.550 \\
\hline & Yunnan & 0.49 & 0.451 & 0.518 & 0.583 & 0.741 & 0.645 & 0.671 & 0.708 & 0.704 & 0.612 \\
\hline & Shaanxi & 0.917 & 0.811 & 0.93 & 0.729 & 0.798 & 0.727 & 0.75 & 0.792 & 0.756 & 0.801 \\
\hline & Gansu & 0.49 & 0.544 & 0.525 & 0.591 & 0.552 & 0.506 & 0.563 & 0.589 & 0.564 & 0.547 \\
\hline & Qinghai & 1 & 1 & 1 & 1 & 1 & 1 & 1 & 1 & 1 & 1 \\
\hline & Ningxia & 1 & 1 & 1 & 1 & 0.706 & 0.734 & 0.745 & 1 & 1 & 0.909 \\
\hline & Xinjiang & 0.899 & 0.939 & 0.823 & 0.894 & 0.859 & 0.699 & 1 & 1 & 1 & 0.901 \\
\hline & Guangxi & 0.503 & 0.431 & 0.456 & 0.51 & 0.473 & 0.496 & 0.511 & 0.524 & 0.53 & 0.493 \\
\hline
\end{tabular}

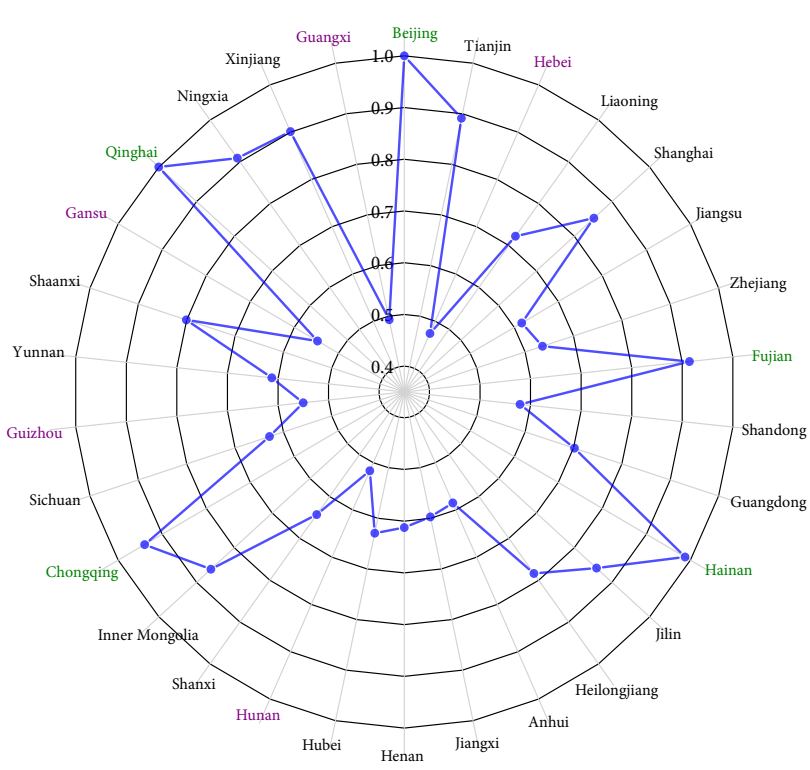

Figure 3. The average of SPS in China's provincial construction industries
It can be inferred that the safety performance of China's provincial construction industries over the past nine years was divided into four groups from the best-performing to underperforming, i.e., Group A, Group B, Group C, and Group D, as shown in Table 5. Four groups form a stepwise upgrade platform of safety performance, which results in provinces that do not show good construction safety performance can learn the successful initiatives taken in by those best-performing ones. Specifically, Beijing, Qinghai, Hainan, Fujian, Chongqing, and Tianjin had a best performing in construction safety over the nineyear period. Among them, four are located in the eastern region, two in the western region. Compared to the rest of the provinces, these six provinces were the frontrunners in terms of construction safety performance, which can be utilized as role models for the provinces that need to improve the condition of construction safety. For those underperforming provinces include Jiangsu, Henan, Shandong, Anhui, Gansu, Jiangxi, Yunnan, Hunan, Guangxi, Hebei, and Guizhou, they are in urgent need of adjustment in safety practices to reach a better performance. 


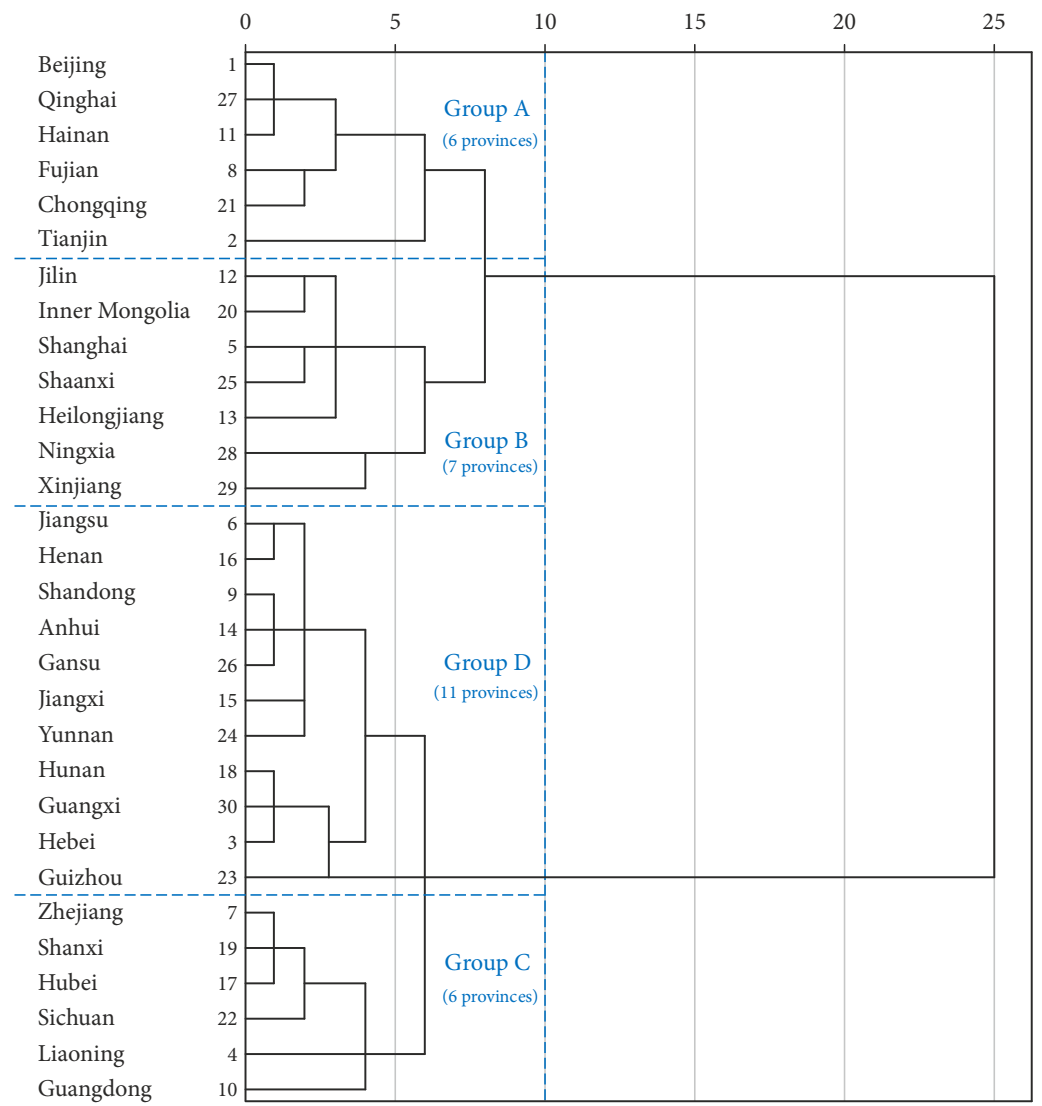

Figure 4. Cluster analysis of safety performance in China's provincial construction industries

Table 5. The grouping of safety performance in China's provincial construction industries

\begin{tabular}{|l|l|}
\hline Grouping & \multicolumn{1}{|c|}{ Province } \\
\hline Group A & Beijing, Qinghai, Hainan, Fujian, Chongqing, Tianjin \\
\hline Group B & Jilin, Inner Mongolia, Shanghai, Shaanxi, Heilongjiang, Ningxia, Xinjiang \\
\hline Group C & Zhejiang, Shanxi, Hubei, Sichuan, Liaoning, Guangdong \\
\hline Group D & Jiangsu, Henan, Shandong, Anhui, Gansu, Jiangxi, Yunnan, Hunan, Guangxi, Hebei, Guizhou \\
\hline
\end{tabular}

\subsection{Region analysis}

From Figure 5 we can observe that the average of SPS in the eastern region is the highest, followed by the western and central region. It will help the scholars have a better understanding of the performance in China's provincial construction safety from the perspective of the spatial dimension. From Figure 6, the low score of DT is the main reason for the reduction of safety performance in the eastern region, the high score of CA is the main reason for the reduction of safety performance in the central region, and the high score of DT is the main reason for the increase of safety performance in the western region. Also, the eastern region has a good performance in economic benefit and the western region in accident prevention. The reasons of the phenomenon are chiefly as follows: (i) The eastern coastal region won the priority development of opportunity in Chinese gradual reform, and the eastern region is the most developed area in China (Du et al., 2014).

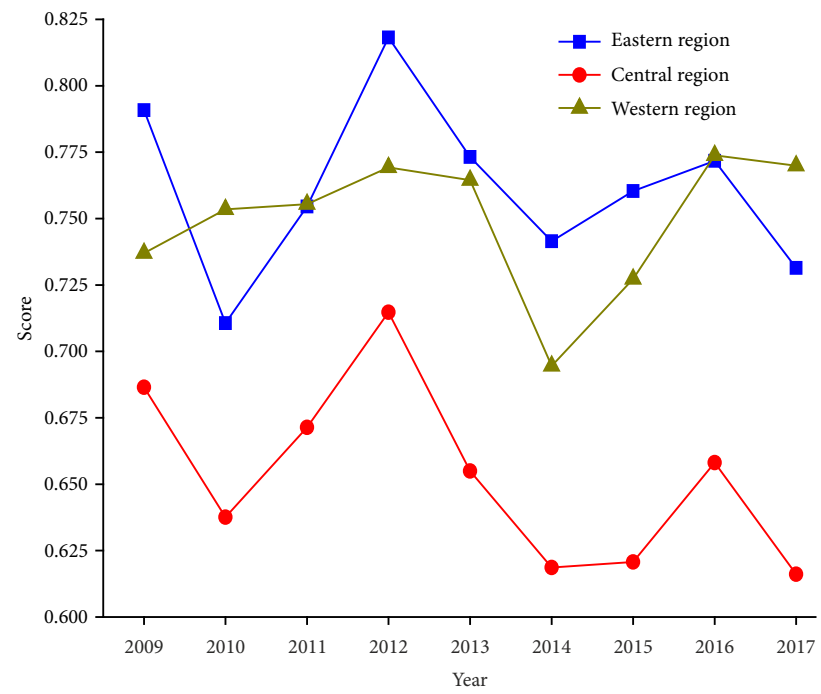

Figure 5. The average of SPS in three main regions from 2009 to 2017 


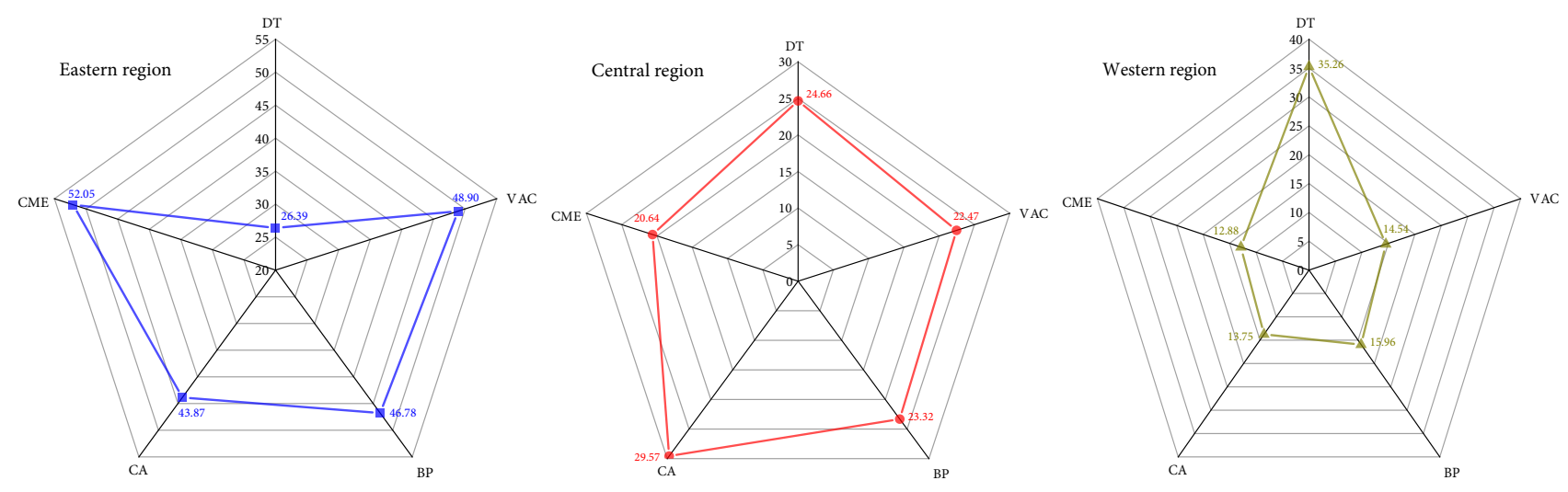

Figure 6. The average score of inputs and outputs in three main regions

Note: The data is pre-processed by Eqns (4)-(7). The higher score of DT, indicating the fewer number of deaths.

Also, the construction industry in the eastern region got development and generated good economic benefit. Although it did not very well in accident prevention, the eastern region still achieved the highest score of safety performance which benefited from good performance in construction economic development. (ii) The central region is one of the dynamic economic region in China and the construction industry has also made great progresses. However, the output-input ratio of the construction safety in the central region was low. It had not utilized input resources for a long time, leading to the lowest score in safety performance. (iii) The economic development is chronically in slow condition for the west region, and the construction industry was at the early stage. However, it achieved the medium score which benefited from good performance in accident prevention.

\subsection{Case analysis}

There are 30 DMUs in this paper. Three DMUs were selected to study case for further analysis, i.e., Jiangsu, Hebei, and Hainan provinces.

Jiangsu as a developed province in the eastern coastal region of China, the construction industry has grown rapidly over the past few years. From Table 6 , the input of Jiangsu such as BP, CME, and CA ranked first or second in China. Also, the desirable and undesirable output such as VAC and DT ranked first or second. It is not quite appropriate to evaluate the safety performance of Jiangsu when undesirable output such as casualty rate is used as the main indicator, considering the inputs occupied 15\% of the national construction industry. It may result in a greater number of construction accidents when faced more amount of exposure to risk (Shen et al., 2012). Because the good performance of construction economic benefit, safety performance of Jiangsu in 2009 ranked 15th instead of the last one or two, and have made the top 20 in four years. From Figure 7, SPS of Jiangsu has decreased in 2010. The main reason for this is that the amount of exposure to risk such as CME and CA have decreased and the percentage of undesirable output has increased, which leads to a drop in the ranking of safety performance from
15 to 21 . In addition, the curve of VAC in Jiangsu has a trend of increase from 2009 to 2017, and the trend for the curves of SPS and DT were on the opposite. It is noteworthy that the SPS increased with an increasing undesirable output in 2016. The reason of the phenomenon is that its economic benefit in the construction industry is significantly higher than the other 29 provinces, namely that construction activity increased faster than the undesirable output. The main challenge of Jiangsu is how to control the undesirable output such as injuries and deaths when keeping on the economic growth currently. Hence, it is important to establish a scientific and effective safety management system to prevent risk in construction sites.

From Table 6, the input of Hebei such as BP and CA ranked around 12th in China, especially the input of CME was approximately ranked 7 th. Meanwhile, the undesirable output of DT ranked around 20th. Safety performance of Hebei should rank among the top ten when the undesirable output such as casualty rate was taken as main indicator. But in reality, its safety performance stayed at the bottom between 2009 and 2017. The reason why the low output-input ratio of Hebei was discussed here. Taking the year 2010 as an example, the scores of inputs such as BP, CME, and CA are 2.524, 6.274, and 2.623, respectively, and the scores of the output of VAC and DT are 1.963 and 7.686, respectively. The output-input ratio of Hebei's construction safety was at the lowest compared to the rest of the provinces, which results in a significant drop in terms of safety performance ranking. From Figure 8, the curves of VAC and SPS share a similar trend. Although it did well in accident prevention, the poor economic performance of construction is the main reason for the sharp drop in safety performance ranking. The main challenge of Hebei is how to increase the utilization rate of input resources in the case of undesirable output declining. So, the improvement of economic benefit is of special importance to the development of Hebei's construction industry during the transitional period.

From Table 6, the input of Hainan such as BP, CME, and CA were at the lower end of the ranking, besides, its VAC ranked last. However, Hainan achieved the high score over the past eight years which benefited from good 
Table 6. The ranking of inputs, outputs, and SPS in Jiangsu, Hebei, and Hainan provinces

\begin{tabular}{|c|c|c|c|c|c|c|c|c|c|c|}
\hline Province & Variable & 2009 & 2010 & 2011 & 2012 & 2013 & 2014 & 2015 & 2016 & 2017 \\
\hline \multirow{6}{*}{ Jiangsu } & SPS & 15 & 21 & 22 & 21 & 27 & 22 & 18 & 17 & 17 \\
\hline & $\mathrm{BP}$ & 1 & 1 & 1 & 1 & 1 & 1 & 2 & 2 & 2 \\
\hline & CME & 1 & 1 & 1 & 1 & 1 & 1 & 1 & 1 & 1 \\
\hline & $\mathrm{CA}$ & 2 & 2 & 2 & 2 & 1 & 1 & 1 & 1 & 1 \\
\hline & VAC & 1 & 1 & 1 & 1 & 1 & 1 & 1 & 1 & 1 \\
\hline & DT & 2 & 1 & 1 & 3 & 1 & 1 & 1 & 1 & 1 \\
\hline \multirow{6}{*}{ Hebei } & SPS & 23 & 26 & 28 & 30 & 30 & 30 & 29 & 30 & 30 \\
\hline & $\mathrm{BP}$ & 13 & 13 & 12 & 12 & 14 & 14 & 14 & 13 & 14 \\
\hline & CME & 7 & 3 & 7 & 7 & 4 & 6 & 7 & 8 & 6 \\
\hline & $\mathrm{CA}$ & 14 & 12 & 12 & 12 & 13 & 13 & 13 & 13 & 13 \\
\hline & VAC & 16 & 16 & 14 & 14 & 15 & 16 & 17 & 16 & 16 \\
\hline & DT & 12 & 17 & 12 & 20 & 26 & 27 & 13 & 26 & 28 \\
\hline \multirow{6}{*}{ Hainan } & SPS & 1 & 1 & 1 & 1 & 1 & 1 & 1 & 1 & 7 \\
\hline & $\mathrm{BP}$ & 28 & 28 & 30 & 30 & 30 & 30 & 30 & 30 & 30 \\
\hline & CME & 30 & 30 & 30 & 30 & 30 & 30 & 30 & 30 & 30 \\
\hline & CA & 29 & 29 & 29 & 29 & 29 & 29 & 29 & 29 & 29 \\
\hline & VAC & 30 & 30 & 30 & 30 & 30 & 30 & 30 & 30 & 30 \\
\hline & DT & 28 & 27 & 27 & 28 & 29 & 27 & 29 & 27 & 25 \\
\hline
\end{tabular}

performance in accident prevention. It is noteworthy that the SPS has fallen dramatically in 2017. The reason of the phenomenon is that the number of deaths in the construction industry is significantly increasing, with the percentage from 0.952 to 1.487 in the year 2016 and 2017. It leads to a drop in the ranking of safety performance from 1 to 7. From Figure 9, the curves of VAC present the undulation type change, with the percentage from 0.114 to 0.163 , which is considerably lower than the average. The curve of DT in Hainan has a trend of decrease from 2009 to 2016, and its SPS is equal to 1.0. It reflects the core of the method is to evaluate the relative effectiveness of DMUs. The main challenge of Hainan is how to increase the construction economic vitality when keeping on current performance of accident prevention.

Compared to the partial-factor indicator, the ranking of safety performance of Jiangsu and Hainan were raised while Hebei dropped. Therefore, using the method to measure the safety performance of the construction industry can improve the performance evaluation system based on the partial-factor indicator.

\subsection{Research limitations}

From the analysis in terms of time dimensions, the DMU have two special phenomena in the ranking of safety performance. Firstly, the SPS has increased, but its ranking has dropped. Secondly, the SPS has decreased, but its ranking has raised. From Figure 10, the change rate of total-factor productivity curve generally shows a trend of rise-down-rise. The change rate of total-factor productivity was less than one in 2010,2013,2014, and 2017, which indicates that there is a decline in the output-input ratio for construction safety compared to the previous year.

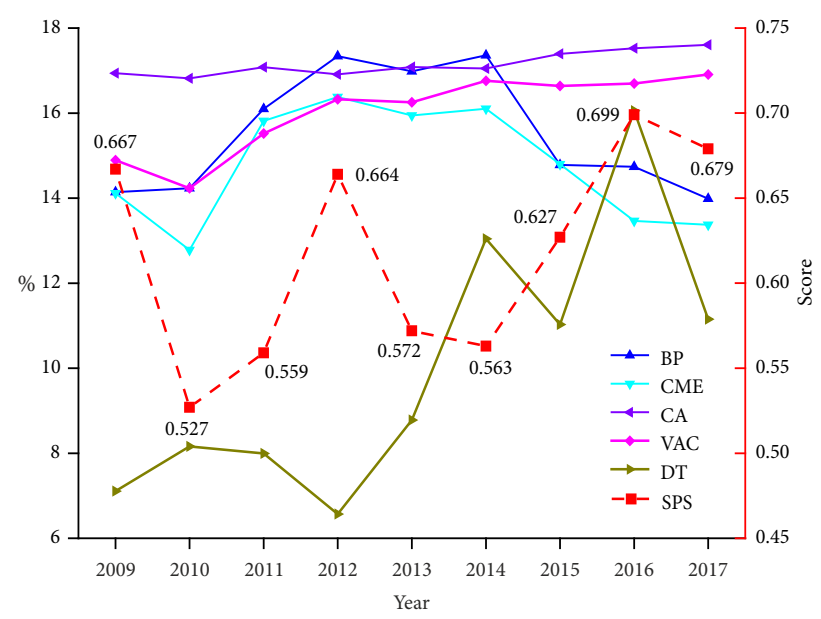

Figure 7. The SPS, inputs, and outputs in Jiangsu province

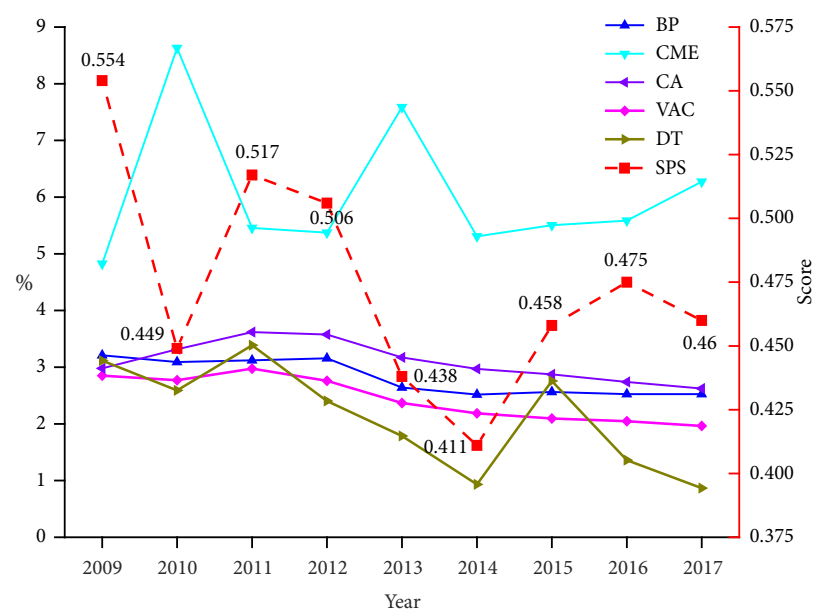

Figure 8. The SPS, inputs, and outputs in Hebei province 


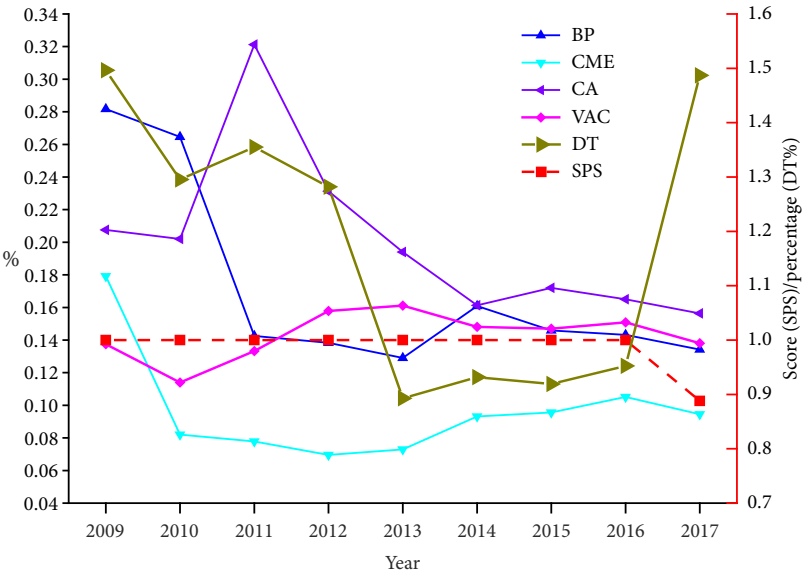

Figure 9. The SPS, inputs, and outputs in Hainan province

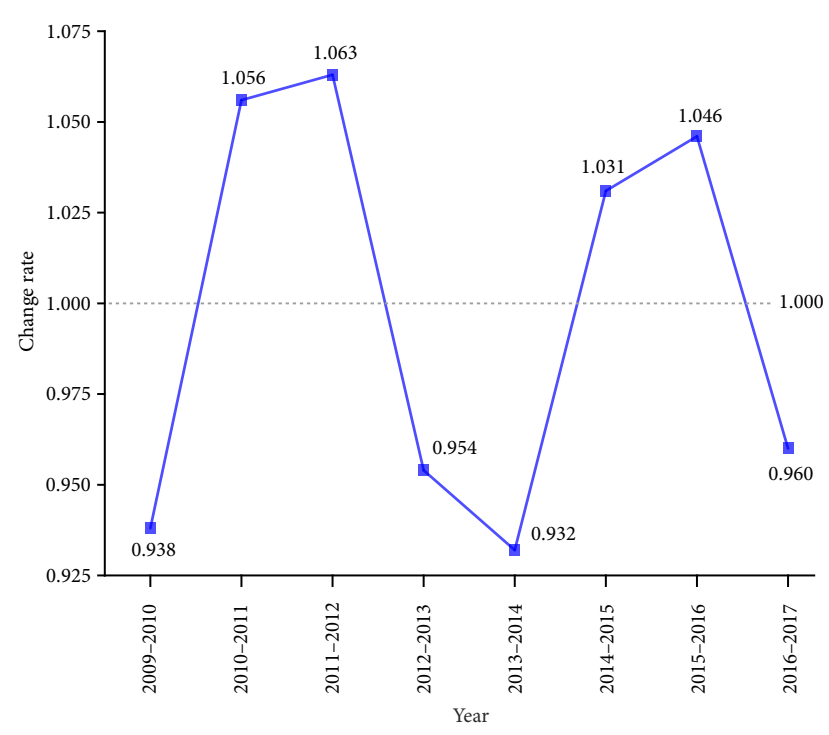

Figure 10. The change rate of total-factor productivity in China's provincial construction industries from 2009 to 2017 Note: Ignoring technical change of the construction industry.

For example, the change rate of total-factor productivity was less than one in the year 2017. The SPS of Jiangsu province is 0.679 in 2017, which is lower than 0.699 in 2016 , and their ranking is consistent. The change rate of total-factor productivity was more than one in 2011,2012 , 2015, and 2016, which indicates that there is an improvement in the output-input ratio for construction safety compared to the previous year. For example, the change rate of total-factor productivity was more than one in the year 2011. The SPS of Yunnan province is 0.518 in 2011, which is higher than 0.451 in 2010, and the ranking dropped by two places. In conclusion, the ranking of safety performance among provinces should be limited to a certain period of time.

\section{Conclusions and future research}

This paper develops a DEA-based framework to evaluate the construction safety performance at the macro level, combining with both the desirable output and the output- input ratio. $\mathrm{BP}, \mathrm{CME}$, and $\mathrm{CA}$ are used as the input, and VAC and DT are used as the output. This study is a significant attempt to use the five indicators for providing an overall perspective on China's provincial construction safety situation compared to the previous research. The core of this study is to compare the output-input ratio of the construction safety, which have reference values for evaluating the safety performance in other countries or regions. This paper evaluates China's provincial construction safety performance over the past nine years, and the key findings are listed as follows:

(i) The gap between the best-performing and underperforming province was relatively small in 2012 and big in 2014. The performance score of construction safety for most provinces vary from year to year. Only the performance score of Beijing and Qinghai are the same (i.e., all efficient) in terms of construction safety over the past nine years. Due to the number of efficient provinces every year is between five and seven, there is much room to improve construction safety performance among most provinces. Some benchmark provinces in one year may not be the ones in the next year. In order to resolve this problem, China's provincial construction safety performance over the past nine years can be divided into four groups from the bestperforming to underperforming. Provinces can further improve their safety performance by learn from the safety practice of those provinces with better performance. Among them, six provinces such as Beijing, Qinghai, Hainan, Fujian, Chongqing, and Tianjin can be utilized as role models for performance improvement of the rest provinces.

(ii) To identify the difference of construction safety performance among regions, 30 provinces were divided into three main regions according to the previous research. The eastern region had the highest score in safety performance, followed by the western and central region. DT, CA, and DT were the main reasons which affect the performance of construction safety in the eastern, central, and western region respectively. Three regions should adopt different countermeasures according to their own situation. Specifically, the eastern region should strengthen construction risk prevention to reduce the number of injuries and deaths, which promotes a more sustainable and healthy development of the construction industry. The central region need strengthen safety management and technology renewal on the basis of existing input resources, then increase the output-input ratio of construction safety. The western region should seize the opportunities such as the western development strategy to extract the management experience from the eastern region success and to bring in talents, which improves the vigor of the economy.

(iii) In order to compare the difference between partialfactor indicators and total-factor indicators, Jiangsu, 
Hebei, and Hainan provinces were separately analyzed. The ranking of construction safety performance in Jiangsu and Hainan were raised while Hebei dropped, which indicates that this approach can improve the tradition performance evaluation system to a certain extent. Due to the change rate of total-factor productivity shows a trend of rise-downrise, the ranking of safety performance among provinces should be limited to a certain period of time. In other words, the score of construction safety performance in different year cannot be compared.

This paper is considered three risk indicators from the perspective of "people-machine-environment" system, but the other factors such as safety measures, safety policies, and safety culture are not introduced as the input. Due to these factors are difficult to quantify at the macro level, it is an urgent problem of the future research. It is noteworthy that other countries or regions may need to make dynamic adjust the input and output indicators based on their own situations, which causes the performance evaluation result to be more accuracy. Combining with the Heinrich's Law (i.e., the 300:29:1 theory), serious or minor injuries as well as the accidents with greater influence in public opinion can be introduced as the undesirable output. However, it requires more greater detailed and an increased abundance of the construction accident information. Moreover, researchers evaluate safety performance by taking into consideration of the theory of scale economies effect. It may provide a more extensive insight related to construction safety for the policymakers. This study could also be further analyzed, for example, it analyzes the impact of technical change on construction safety performance by using the method such as Malmquist productivity index.

\section{Funding}

This work was supported by the $<$ National Natural Science Foundation of China> under Grant [number 51534008]; $<$ Fundamental Research Funds for the Central Universities of Central South University> under Grant [number 2019zzts304]

\section{Author contributions}

Liangguo KANG was responsible for manuscript writing and editing, data analysis, content planning. Chao WU was responsible for manuscript editing, content planning.

\section{Disclosure statement}

Authors do not have any competing financial, professional, or personal interests from other parties.

\section{References}

Awolusi, I. G., \& Marks, E. D. (2016). Safety activity analysis framework to evaluate safety performance in construction.
Journal of Construction Engineering and Management, 143(3), 05016022 .

https://doi.org/10.1061/(ASCE)CO.1943-7862.0001265

Barak, S., \& Dahooei, J. H. (2018). A novel hybrid fuzzy DEAFuzzy MADM method for airlines safety evaluation. Journal of Air Transport Management, 73, 134-149.

https://doi.org/10.1016/j.jairtraman.2018.09.001

Bastos, J. T., Shen, Y., Hermans, E., Brijs, T., Wets, G., \& Ferraz, A. C. P. (2015). Traffic fatality indicators in Brazil: State diagnosis based on data envelopment analysis research. Accident Analysis \& Prevention, 81, 61-73.

https://doi.org/10.1016/j.aap.2015.01.024

Boyd, G. A. (2008). Estimating plant level energy efficiency with a stochastic frontier. The Energy Journal, 29(2), 23-43.

https://doi.org/10.5547/ISSN0195-6574-EJ-Vol29-No2-2

Chen, Y., Liu, B., Shen, Y., \& Wang, X. (2016). The energy efficiency of China's regional construction industry based on the three-stage DEA model and the DEA-DA model. KSCE Journal of Civil Engineering, 20(1), 34-47. https://doi.org/10.1007/s12205-015-0553-3

Choudhry, R. M. (2017). Achieving safety and productivity in construction projects. Journal of Civil Engineering and Management, 23(2), 311-318.

https://doi.org/10.3846/13923730.2015.1068842

Dou, E. W., \& Zheng, X. Y. (2011, August). Evaluation of contractors' safety performance based on DEA. In 2011 International Conference on Management and Service Science. Wuhan, China. https://doi.org/10.1109/ICMSS.2011.5998194

Du, K., Lu, H., \& Yu, K. (2014). Sources of the potential $\mathrm{CO}_{2}$ emission reduction in China: A nonparametric metafrontier approach. Applied Energy, 115, 491-501. https://doi.org/10.1016/j.apenergy.2013.10.046

El-Mashaleh, M. S., Minchin Jr., E. R., \& O’Brien, W. J. (2007). Management of construction firm performance using benchmarking. Journal of Management in Engineering, 23(1), 10-17. https://doi.org/10.1061/(ASCE)0742-597X(2007)23:1(10)

El-Mashaleh, M. S., Rababeh, S. M., \& Hyari, K. H. (2010). Utilizing data envelopment analysis to benchmark safety performance of construction contractors. International Journal of Project Management, 28(1), 61-67. https://doi.org/10.1016/j.ijproman.2009.04.002

Feng, C., \& Wang, M. (2017). The economy-wide energy efficiency in China's regional building industry. Energy, 141, 1869-1879. https://doi.org/10.1016/j.energy.2017.11.114

Feng, C., Zhang, H., \& Huang, J. B. (2017). The approach to realizing the potential of emissions reduction in China: An implication from data envelopment analysis. Renewable and Sustainable Energy Reviews, 71, 859-872. https://doi.org/10.1016/j.rser.2016.12.114

Ganji, S. R. S., \& Rassafi, A. A. (2019). Measuring the road safety performance of Iranian provinces: a double-frontier DEA model and evidential reasoning approach. International Journal of Injury Control and Safety Promotion, 26(2), 156-169. https://doi.org/10.1080/17457300.2018.1535510

General Administration of Quality Supervision, Inspection and Quarantine of PRC (GAQSIQ), Standardization Administration of PRC. (2017, June 30). Industrial classification for national economic activities (Revised ed.). Standards Press of China.

Geng, Z., Dong, J., Han, Y., \& Zhu, Q. (2017). Energy and environment efficiency analysis based on an improved environment DEA cross-model: Case study of complex chemical processes. Applied Energy, 205, 465-476. https://doi.org/10.1016/j.apenergy.2017.07.132 
Geng, Z., Zeng, R., Han, Y., Zhong, Y., \& Fu, H. (2019). Energy efficiency evaluation and energy saving based on DEA integrated affinity propagation clustering: Case study of complex petrochemical industries. Energy, 179, 863-875.

https://doi.org/10.1016/j.energy.2019.05.042

Han, Y., Long, C., Geng, Z., \& Zhang, K. (2018). Carbon emission analysis and evaluation of industrial departments in China: An improved environmental DEA cross model based on information entropy. Journal of Environmental Management, 205, 298-307. https://doi.org/10.1016/j.jenvman.2017.09.062

Han, Y., Long, C., Geng, Z., Zhu, Q., \& Zhong, Y. (2019). A novel DEACM integrating affinity propagation for performance evaluation and energy optimization modeling: Application to complex petrochemical industries. Energy Conversion and Management, 183, 349-359.

https://doi.org/10.1016/j.enconman.2018.12.120

Hu, J. L., \& Wang, S. C. (2006). Total-factor energy efficiency of regions in China. Energy Policy, 34(17), 3206-3217. https://doi.org/10.1016/j.enpol.2005.06.015

$\mathrm{Hu}, \mathrm{X} .$, \& Liu, C. (2018). Measuring efficiency, effectiveness and overall performance in the Chinese construction industry. Engineering, Construction and Architectural Management, 25(6), 780-797. https://doi.org/10.1108/ECAM-06-2016-0131

Ji, T., Wei, H. H., \& Chen, J. (2019). Understanding the effect of co-worker support on construction safety performance from the perspective of risk theory: an agent-based modeling approach. Journal of Civil Engineering and Management, 25(2), 132-144. https://doi.org/10.3846/jcem.2019.7642

Kang, L., Wu, C., \& Wang, B. (2019). Principles, approaches and challenges of applying big data in safety psychology research. Frontiers in Psychology, 10, 1596.

https://doi.org/10.3389/fpsyg.2019.01596

Kang, L., Wu, C., Liao, X., \& Wang, B. (2020). Safety performance and technology heterogeneity in China's provincial construction industry. Safety Science, 121, 83-92.

https://doi.org/10.1016/j.ssci.2019.09.005

Li, Y., Chiu, Y. H., \& Lin, T. Y. (2019). Coal production efficiency and land destruction in China's coal mining industry. Resources Policy, 63, 101449.

https://doi.org/10.1016/j.resourpol.2019.101449

Liu, Q., Meng, X., Hassall, M., \& Li, X. (2016). Accident-causing mechanism in coal mines based on hazards and polarized management. Safety Science, 85, 276-281. https://doi.org/10.1016/j.ssci.2016.01.012

McCabe, B. Y., Alderman, E., Chen, Y., Hyatt, D. E., \& Shahi, A. (2016). Safety performance in the construction industry: Quasi-longitudinal study. Journal of Construction Engineering and Management, 143(4), 04016113.

https://doi.org/10.1061/(ASCE)CO.1943-7862.0001260

Ministry of Housing and Urban-Rural Development of PRC. (2016, July 9). Technical code for working safety at height of building construction. China Architecture \& Building Press.

Nahangi, M., Chen, Y., \& McCabe, B. (2019). Safety-based efficiency evaluation of construction sites using data envelopment analysis (DEA). Safety Science, 113, 382-388. https://doi.org/10.1016/j.ssci.2018.12.005

National Bureau of Statistics of PRC. (2018). China statistical yearbook 2018. China Statistics Press.

Nazarko, J., \& Chodakowska, E. (2017). Labour efficiency in construction industry in Europe based on frontier methods: Data envelopment analysis and stochastic frontier analysis. Journal of Civil Engineering and Management, 23(6), 787-795. https://doi.org/10.3846/13923730.2017.1321577
Pugalis, L., \& Tan, S. (2017). Metropolitan and regional economic development: Competing and contested local government roles in Australia in the 21st century. In Proceedings of the 40th Annual Conference of the Australian and New Zealand Regional Science Association International. Melbourne, Australia.

Seiford, L. M., \& Zhu, J. (2002). Modeling undesirable factors in efficiency evaluation. European Journal of Operational Research, 142(1), 16-20. https://doi.org/10.1016/S0377-2217(01)00293-4

Shen, Y., Hermans, E., Bao, Q., Brijs, T., \& Wets, G. (2013). Road safety development in Europe: A decade of changes (20012010). Accident Analysis \& Prevention, 60, 85-94. https://doi.org/10.1016/j.aap.2013.08.013

Shen, Y., Hermans, E., Brijs, T., Wets, G., \& Vanhoof, K. (2012). Road safety risk evaluation and target setting using data envelopment analysis and its extensions. Accident Analysis \& Prevention, 48, 430-441.

https://doi.org/10.1016/j.aap.2012.02.020

Stern, D. I. (2012). Modeling international trends in energy efficiency. Energy Economics, 34(6), 2200-2208. https://doi.org/10.1016/j.eneco.2012.03.009

Tatari, O., Egilmez, G., \& Kurmapu, D. (2016). Socio-eco-efficiency analysis of highways: a data envelopment analysis. Journal of Civil Engineering and Management, 22(6), 747-757. https://doi.org/10.3846/13923730.2014.914079

Wanberg, J., Harper, C., Hallowell, M. R., \& Rajendran, S. (2013). Relationship between construction safety and quality performance. Journal of Construction Engineering and Management, 139(10), 04013003.

https://doi.org/10.1061/(ASCE)CO.1943-7862.0000732

Wang, B., Wu, C., Kang, L., Reniers, G., \& Huang, L. (2018). Work safety in China's thirteenth five-year plan period (20162020): Current status, new challenges and future tasks. Safety Science, 104, 164-178.

https://doi.org/10.1016/j.ssci.2018.01.012

Wang, L., Yan, G., \& Cai, H. (2012). Evaluation of building industry safety situation based on synthetic equivalent mortality method. China Safety Science Journal, 22(9), 10-15 (in Chinese).

Xue, X., Shen, Q., Wang, Y., \& Lu, J. (2008). Measuring the productivity of the construction industry in China by using DEA-based Malmquist productivity indices. Journal of Construction Engineering and Management, 134(1), 64-71. https://doi.org/10.1061/(ASCE)0733-9364(2008)134:1(64)

Zhang, J., Zhang, W., Xu, P., \& Chen, N. (2019a). Applicability of accident analysis methods to Chinese construction accidents. Journal of Safety Research, 68, 187-196. https://doi.org/10.1016/j.jsr.2018.11.006

Zhang, W., Zhang, X., Luo, X., \& Zhao, T. (2019b). Reliability model and critical factors identification of construction safety management based on system thinking. Journal of Civil Engineering and Management, 25(4), 362-379. https://doi.org/10.3846/jcem.2019.8652

Zhou, Y., Liu, W., Lv, X., Chen, X., \& Shen, M. (2019). Investigating interior driving factors and cross-industrial linkages of carbon emission efficiency in China's construction industry: Based on Super-SBM DEA and GVAR model. Journal of Cleaner Production, 241, 118322. https://doi.org/10.1016/j.jclepro.2019.118322 